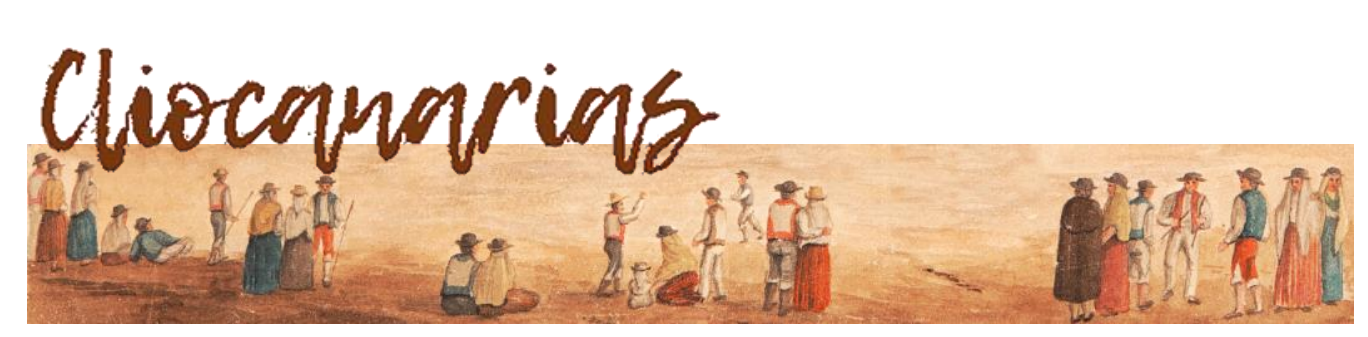

ISSN 2695-4494

https://doi.org/10.53335/cliocanarias.2021.3.03

\title{
CONSENSO Y VIOLENCIA EN LOS REGÍMENES FASCISTA, NACIONALSO- CIALISTA Y FRANQUISTA: UN ESTADO DE LA CUESTIÓN.
}

\author{
CONSENSUS AND VIOLENCE IN THE FASCIST, NATIONAL-SOCIALIST AND FRAN- \\ COIST REGIMES: A STATE OF THE QUESTION
}

Julio HERNÁNDEZ ABREU*

\begin{abstract}
RESUMEN: Se presenta un recorrido historiográfico a través del fenómeno del consenso que busca conocer cuáles han sido las principales ideas esbozadas por distintos autores e historiadores acerca de los apoyos sociales otorgados a las dictaduras de Adolf Hitler, Benito Mussolini y Francisco Franco. Se buscará entender cuál fue la importancia de la violencia y la coacción como mecanismos de consenso y qué otras herramientas institucionales se llevaron a cabo para obtener la fidelidad de la población.
\end{abstract}

PALABRAS CLAVE: fascismo, consenso, consentimiento, violencia, coerción.

ABSTRACT: A historiographical journey is presented through the phenomenon of consensus that seeks to know what have been the main ideas outlined by different authors and historians about the social support given to the dictatorships of Adolf Hitler, Benito Mussolini and Francisco Franco. Itwill seek to understand the importance of violence and coercion as consensus mechanisms and whatother institutional tools were used to obtain the loyalty of the population. KEYWORDS: fascism, consensus, consent, violence, coercion.

\section{Una evolución historiográfica}

¿Qué llevó a la población a abrazar al fascismo? ¿Qué encontró la ciudadanía en Adolf Hitler, Benito Mussolini y Francisco Franco que les indujo a servir fielmente a sus propósitos? ¿Cómo es posible que en un gobierno carente de libertades democráticas pudiera existir la complicidad ciudadana? ¿Qué porcentaje ocupó la violencia y la coacción en la conformación del consenso? ¿Fue uniforme este fenómeno o hubo numerosos factores circunstanciales que dieron pie a la formación de "zonas grises»? ¿Qué vías y mecanismos emplearon

\footnotetext{
* Graduado en Historia. C. e.: juliohernandezabreu@gmail.com
} 
los dictadores para ganarse el apoyo popular? Estas y otras preguntas similares han centrado la atención de diversos investigadores y académicos de distinta nacionalidad que a lo largo de los últimos años se han tratado de resolver gracias a la aportación de nuevas fuentes y la introducción de nuevas metodologias y perspectivas analiticas. Muchas son las similitudes y diferencias existentes entre el fascismo italiano, el nacionalsocialismo alemán y el franquismo, siendo necesario indicar qué paralelismos sociopolíticos pueden deducirse de su génesis, evolución histórica, consolidación y conclusión en el marco de su actitud ante la población.

La historiografia antifascista, tras la conclusión de la Segunda Guerra Mundial, no dio lugar a la interpretación del fascismo como una ideología capaz de convertirse en un fenómeno de masas, intentando de este modo evitar su justificación o legitimización a través del controvertido concepto de consenso. Después de 1945, la investigación histórica italiana se centró en la resistencia antifascista: se presentó al pueblo italiano como una víctima y no como un colaborador. En otras palabras, esta primera visión ortodoxa defendió que un alto porcentaje de la población italiana rechazó el régimen de Mussolini y que solo este y sus más fieles seguidores son los verdaderos culpables de los crimenes perpetrados. Será a partir de la década de los sesenta del siglo XX cuando se lleven a cabo nuevas perspectivas analiticas que permitan profundizar en la idea de un consentimiento por parte de la población a los regímenes fascistas; en la idea de que, más allá de la demagogia y la violencia, el fascismo había sabido aunar el descontento y las aspiraciones de diversos grupos sociales. Por tanto, se han ido configurando en las últimas décadas dos tendencias historiográficas principales, dos líneas de investigación que han girado, por un lado, en la enfatización de la represión y el miedo y, por otro lado, en la idea del consenso a través de la acentuación de las estructuras ideológicas y culturales.

En cuanto al nacionalsocialismo, hasta la década de los sesenta prevaleció una historiografia orientada a destacar el ámbito institucional y estatal del Tercer Reich y sus armas de convicción, relegando a un segundo plano cualquier interpretación social o cualquier interés por la mentalidad colectiva de la población que constituía el régimen. En la nueva reinterpretación del nazismo desarrollada a partir de los años setenta - en la que destacarán autores como Martin Broszat y Hans Mommsen y que se enmarcará dentro de la denominada "nueva historia de la tercera generación de Annales" - se resaltarán los apoyos electorales dados al NSDAP. La importancia del discurso simbólico como herramienta de modelación conductual y afianzamiento del consenso cobraría interés ya en la década de los noventa, utilizando la historiografia, para su análisis, todos aquellos ejemplos de denuncia social o señalamiento llevados a cabo por individuos que habian interiorizado los preceptos ideológicos del régimen frente a aquellos que se mostraban contrarios a este.

Crecía asi durante esos años una historiografia que otorgaba un papel significativo a la identificación popular de las propuestas impulsadas por el nacionalsocialismo: la Alltagsgeschichte (historia de la vida cotidiana) permitió llevar a cabo investigaciones que fueran más allá del análisis "de arriba abajo" y se adentraran en las diversas actitudes ciudadanas. Los continuos vaivenes 
que otorgarán prioridad a las actuaciones policiales y los servicios de inteligencia en el momento de imponer a la población una actitud sumisa ante el Estado o el énfasis otorgado a la función desempeñada por esta última a la hora de perseguir a determinados colectivos - especialmente los judíos- vertebrarán los análisis historiográficos de los años posteriores. Cada vez más voces se alzarán en favor de esta segunda propuesta, especialmente a partir del siglo XXI, destacando la complicidad de la sociedad alemana en el exterminio racial nazi. Un papel activo de la población no judía - si tenemos en cuenta su participación en los ataques - o pasivo - si lo que destacamos es su indiferencia, consentimiento o conformidad ante la aniquilación y el exterminio (sin que ello significara un entusiasmo y un respaldo público y manifiesto)-, cimentado en un discurso antisemita de exaltación de las bases étnicas y biológicas de la nación germánica frente a las amenazas del bolchevismo y del judaísmo. Esta exaltación buscaba generar un sentimiento de autoidentificación del ciudadano alemán con determinados valores éticos y culturales.

Los estudios sobre el comportamiento social en época franquista experimentaron un importante crecimiento a partir del acceso de los investigadores a documentación gubernamental, especialmente a los fondos de instituciones y organismos de control social como las jefaturas provinciales de FET-JONS o la OSE, cuyos informes se destinaban a la comunicación de la situación politica en su ámbito territorial. También incrementó su relevancia la utilización de fuentes orales, como demostrarán los estudios de Jordi Font para el caso de Girona. Bebiendo del debate historiográfico generado en Italia, los académicos españoles comenzaron a abordar el tema del consenso a partir de finales de los años ochenta, especialmente en Cataluña, donde se celebraría un seminario en 1987 sobre resistencia y apoyo en los primeros años del franquismo. Siguiendo la estela de los trabajos italianos, autores como Francesco Barbagallo, Silvio Lanaro o Borja de Riquer contribuyeron al estudio de las actitudes politicas durante la dictadura de Franco, llevando a cabo estos dos últimos una investigación comparada a partir del análisis del régimen de Mussolini. Poco a poco surgirán voces que intenten demostrar la imposibilidad del uso exclusivo de mecanismos represivos por parte del régimen teniendo en cuenta su perdurabilidad en el tiempo. Ahora bien, estos primeros trabajos incidian en la dicotomía resistencia/consenso sin tener en cuenta el amplio abanico de opiniones y posiciones politicas que pudo llegar a darse a partir de 1936. Además, estaban enfocados especialmente en el denominado primer franquismo, cobrando las clases trabajadoras y las clases medias mayor atención que los grupos burgueses. En 1999 adquirió gran importancia el "Proyecto Valencia", un conjunto de investigaciones basadas en análisis de ámbito local sustentados en la historia desde abajo británica, la "Alltagsgeschichte" alemana y la microhistoria italiana ${ }^{1}$, donde destacarán los trabajos de Ismael Saz, J. Alberto Gómez Roda o Ramiro Reig. A lo largo de la primera década del siglo XX aumentaron las indagaciones en torno a dos campos de estudio: los apoyos sociales al franquismo (que retrotraen la visión analitica a la composición de las fuerzas sublevadas que derribaron la II República y que permiten

\footnotetext{
${ }^{1}$ HERNÁNDEZ BURGOS, Claudio: "Más allá del consenso y la oposición: las actitudes de la "gente corriente" en regimenes dictatoriales. Una propuesta de análisis desde el régimen franquista", en Revista de Estudios Sociales, n. ${ }^{\circ}$ 50, 2014, p. 93.
} 
entender la fractura social de años posteriores) y las actitudes de los españoles durante la dictadura en el marco de la creación, por parte del régimen, de diversos mecanismos de atracción social.

\section{Renzo de Felice, el autor del consenso}

\subsection{Polémicas y controversias}

Si bien Renzo de Felice (1929-1996) nunca se consideró un revisionista historiográfico, la publicación en 1965 del primer volumen biográfico de Mussolini, Il Rivoluzionario: 1883-1920, cambió la percepción que existía sobre él. Las críticas que recibió desde del área marxista y liberal-demócrata giraron en torno a las bases sociales del fascismo, la existencia de una ideología y de una cultura fascistas y el consenso o la violencia en la base del régimen mussoli$n_{\text {niano }}{ }^{2}$. De Felice afirmó, cuando vio la luz el tercer tomo de la mencionada biografia -Mussolini il Duce: Gli anni del consenso 1929-1936-, que el régimen fascista, tras la consolidación de la dictadura en la segunda mitad de la década de 1920, contó con un generalizado consenso, que perduró al menos hasta mediados de la década siguiente. Se trataria de un apoyo social sustentado en la pequeña burguesía y las clases medias, víctimas principales de la situación económica, que encontraron en el fascismo una vía de recuperación tras la Gran Guerra, de afianzamiento social y protagonismo politico frente al proletariado y la gran burguesía, contraria a los intereses sociales y económicos de la élite fascista. Véase, por ejemplo, el deseo de esta última por convertirse en una clase dirigente autónoma y sus pretensiones de intervencionismo estatal. Unas clases medias, en cualquier caso, emergentes y no decadentes ${ }^{3}$, alejadas de cualquier proceso de proletarización. Será en 1975, en Intervista sul fascismo, cuando De Felice distinguió entre fascismo como movimiento revolucionario y renovador y fascismo como régimen, basado en la política de Mussolini. Un movimiento que propugnó la movilización de las masas y la creación de un hombre nuevo ${ }^{4}$ y que encontró premio a través del consenso de gran parte de la población italiana; un régimen que, finalmente, logró un compromiso con la tradicional y antigua estructura burocrática, exaltando los valores del nacionalismo y la figura del líder carismático. Se ha señalado, además, que el autor reatino hablaba de un consenso material y un consenso moral: el primero, fundamentado en la seguridad que daba a los italianos el régimen fascista; el segundo, surgido a partir de la atracción que suponía para los jóvenes la nueva sociedad ofrecida por el movimiento. Es necesario señalar la polémica que generó De Felice en su gremio, ya que su obra se llegó a interpretar como una apología del fascismo. Al fin y al cabo, sus conclusiones rompian el mito de la resistencia antifascista y la idea de un régimen impuesto por la fuerza al pueblo italiano por parte de una minoría.

Entre sus detractores destacó Guido Quazza, defensor de la idea de un fascismo conformado por fuerzas sociales violentas que carecian de cultura e

2 CANALI, Mauro: "Il revisionismo storico e il fascismo", en Cercles: Revista d'historia cultural, n. ${ }^{\circ} 14,2011$, p. 84.

${ }^{3}$ TRANIELLO, Francesco: "Historiografia italiana e interpretaciones del fascismo", en Ayer, n. ${ }^{\circ}$ 36, 1999, p. 191.

${ }^{4}$ GONZÁLEZ CUEVAS, Pedro Carlos: "Renzo de Felice, una semblanza intelectual a los veinte años de su muerte", en Historia y Política, n. ${ }^{\circ} 34,2016$, p. 376. 
ideologia, así como Alberto Aquarone, que afirmaba que a pesar de haberse producido un consenso contaría con un carácter conservador y no tanto revolucionario. La violencia - según estos autores- adquiere así un papel más significativo que el que encontramos en las tesis de Renzo De Felice. La historiografia hegemónica de los años setenta intentaría entonces de alguna manera frenar dichas tesis, especialmente la marxista, que concebia al fascismo como un movimiento reaccionario, adscrito a las élites italianas, al poder eclesiástico, militar y judicial. Giovanni De Luna se mostrará especialmente crítico con la idea de consenso, cuya existencia es constatada por De Felice, pero careciendo de una explicación interpretativa y otorgándole una fe desproporcionada a los documentos oficiales. El historiador del fascismo subestima también la influencia de la represión en la consolidación de dicho consenso. Este sería resultado de elementos coercitivos (indirectos en muchos casos; intimidatorios o psicológicos) de escaso análisis por parte de De Felice. La perdurabilidad del régimen de Mussolini se sustentaría en la difusión de una red de órganos policiales, servicios de inteligencia y cuerpos de vigilancia ${ }^{5}$, que controlarian los espacios más íntimos y privados del ciudadano a través de espías y confidentes.

El historiador Paul Corner considera que la idea del autor italiano de un apoyo social general a Mussolini surge como consecuencia, no de la escasa existencia real de crítica o desaprobación, sino de su imposible manifestación pública por miedo a represalias. Si no hay registro de protestas populares, el consenso parece mayoritario; la no existencia de un Auschwitz italiano ${ }^{6}$ no implica la ausencia de represión. La conformidad puede ser fingida y pasiva de cara a eludir la marginación o el castigo. Así, el significado de "consentimiento" está sesgado: al no haber otras opciones que no impliquen represión, la aceptación se convierte en la vía más fácil de seguir (pero también, al mismo tiempo, se transforma en una fuente de manipulación de la realidad social). Respecto a Corner, afirmaba De Felice que su punto de vista es curiosamente unidimensional. El escritor inglés considera que, al no encontrar su homólogo italiano evidencias explícitas de protesta y si encontrar, por el contrario, a muchos individuos dispuestos a dar apoyo vocal y material al régimen ${ }^{7}$, concluía erróneamente que existía un beneplácito generalizado.

\subsection{No solo De Felice}

Frente a estos detractores, el historiador George L. Mosse se alzará como uno de los grandes partidarios de las ideas de De Felice, afirmando que en la construcción del régimen fascista habian ejercido un papel importante los intelectuales, ya que dotaron al movimiento de un componente cultural que iba más allá de la simple exhibición de retórica y demagogia que defendia la historiografia tradicional. Las manifestaciones masivas, las concentraciones y ceremonias serán para Mosse un momento de agregación de las masas con el fin

\footnotetext{
${ }^{5}$ COBO ROMERO, Francisco: "Los apoyos sociales a los regimenes fascistas y totalitarios de la Europa de entreguerras. Un estudio comparado", en Historia Social, n. ${ }^{\circ}$ 71, 2011, p. 68. ${ }^{6}$ CORNER, Paul: "Italian Fascism: Whatever Happened to Dictatorship?", en The Journal of Modern History, n. ${ }^{\circ}$ 74, 2002, p. 332.

${ }^{7}$ Ibid., pp. 328-329.
} 
de transmitirles un sentimiento de participación en la identidad colectiva ${ }^{8}$. En décadas posteriores, el análisis del fascismo cobrará fuerza no sólo como un fenómeno económico y social, sino también como un movimiento ideológico o cultural. A ello se añade que el ala crítica del revisionismo respecto al fascismo acabó adquiriendo una nueva actitud, manifestada en el congreso organizado en mayo de 1982 por parte del Instituto Gramsci. Los historiadores más "ortodoxos" abandonaron la postura defendida por Guido Quazza (en la que al fascismo se le suponía una violencia intrinseca y univoca) y se abrieron a la idea de consenso.

En otras palabras, se superó el análisis de la coerción violenta como principal arma de poder hegemónico, adentrándonos en la importancia de la difusión del discurso ideológico como base de legitimación. La cultura y el lenguaje (visual, escenográfico, propagandístico, etc.) se convierten así en herramientas de poder y manipulación social. Philip Cannistraro, en este sentido, analizará en los años setenta la labor del Ministero della Cultura Popolare, cuyo funcionamiento en Italia entre 1937 y 1944 -en lo relativo al control del cine, la música o la radio- demostrará la utilidad de la cultura popular como herramienta de consolidación de la identidad nacional. Otros elementos como, por ejemplo, la arquitectura - sobre la que Dianne Ghirardo habla en City and Theater: The Rhetoric of Fascist Architecture-, también se convierten en simbolos de identificación colectiva, jugando un papel importante en la creación del nuevo hombre y la sociedad fascistas, mitos centrales de la ideología fascista ${ }^{9}$.

\section{La Italia fascista}

\subsection{La violencia en los cimientos del movimiento}

Paul Corner llegó a afirmar que la situación política de Italia había invitado a adoptar por parte de ciertos sectores sociales una posición autojustificativa y autoexculpatoria respecto al fascismo, realizando una revisión histórica en una dirección favorable con el objetivo de socavar la autoridad de la posición antifascista $^{10}$. Además, tratar de encontrar las motivaciones de los distintos contendientes en la guerra -defiende el historiador inglés-implicaría equiparar fascistas con antifascistas al considerar que todas las opiniones son aceptables. Perdonar las acciones cometidas por los seguidores de Mussolini supondria, de alguna manera, aceptarlas; su condena se rechazaría por estar basada en prejuicios ideológicos. Carga de esta manera el autor contra el revisionismo y su intento de "rehabilitar" el régimen fascista. Al escribir Italian Fascism: Whatever Happened to Dictatorship? buscaba reivindicar el papel de la represión -descuidado en favor del consenso de masas-y las herramientas de control social no necesariamente represivas que también se llevaron a

\footnotetext{
8 CANALI, Mauro: "Il revisionismo storico...", art. cit., p. 94.

9 NELIS, Jan: "Italian fascism and culture: some notes of investigation", en Haol, n. ${ }^{\circ}$ 9, 2006, p. 144.

10 CORNER, Paul: "Italian Fascism: Whatever Happened...", art. cit., pp. 326-327.
} 
cabo. En esta línea, Giulia Albanese demostró no tener dudas sobre la importancia que ejerció la violencia en la consolidación en el poder del fascismo desde el final de la Primera Guerra Mundial (1914-1918).

A partir de las elecciones locales de 1920 los fascistas, organizados en escuadras armadas de base paramilitar, ocuparán un papel significativo en la coacción, el hostigamiento y la amenaza contra opositores de distintos partidos y asociaciones, especialmente socialistas y radicales de izquierda, con el beneplácito en muchas ocasiones de las fuerzas del orden. La violencia, por tanto, encontró el respaldo de las élites gubernamentales y los terratenientes agrarios, contrarios a las demandas de los trabajadores rurales. Al mismo tiempo, el fascismo consiguió la adhesión de sectores juveniles de clase media baja en detrimento del Partido Socialista. Ahora bien, el profesor coreano Yong-Woo sostiene que el consenso coaccionado fue una situación temporal ya que, una vez caídos los aparatos de propaganda y terror, un gran porcentaje del pueblo italiano se unió a la resistencia.

Hace una década Francisco Cobo Romero, catedrático de Historia Contemporánea de la Universidad de Granada, elaboró una síntesis comparativa entre los distintos regimenes fascistas y totalitarios europeos y sus apoyos sociales. En ella, en primer término, reseñaba la escasa cantidad de fuentes y registros que nos podrian testimoniar las impresiones, opiniones, estados de ánimo o sensaciones políticas de la población. Posteriormente, destacaba la ausencia de un auténtico consenso general y una opinión pública real al no existir unos medios de comunicación libres que permitieran difundir y exponer las diversas ideas, opiniones, impresiones, controvertidas o criticas, de la gente de a pie. Ahora bien, continúa afirmando que a pesar de los métodos de represión y coacción, la falta de libertades y la continua vigilancia, siempre hubo espacio en la intimidad para el desacato o la disidencia. Todo ello, y a pesar de lo dicho, sin negar la leve identificación de algunos grupos sociales con determinados mensajes ideológicos combinada con el rechazo a diversas prácticas represivas; o, directamente, la clara aceptación por parte de algunos sectores sociales del discurso político del régimen desde un sentido alentador y cargado de esperanzadoras expectativas ${ }^{11}$.

\section{2. ¿Solo represión?}

Consolidado en el poder, el objetivo del fascismo ya no solo será movilizar a determinados grupos sociales, sino convertir a todo el conjunto de la población en un pilar básico del movimiento. Al mismo tiempo que se producia el giro totalitario del Estado en la segunda mitad de la década de 1930 y la política exterior agresiva - como demostrará la segunda guerra ítalo-etiope entre 1935 y 1936- se pretendió conformar una nueva mentalidad comunitaria y una concepción supranacional de la civilización a través de los medios de comunicación, los espectáculos multitudinarios y la reciprocidad entre los italianos de a pie y los fascistas. De Emilio Gentile, afirma Cobo Romero, es innegociable su empeño en mostrar al fascismo como una religión política, donde el individuo se subordina al Estado, buscando crear así un "hombre nuevo"; un Estado antiliberal, que busca la regeneración nacional, con

${ }^{11}$ COBO ROMERO, Francisco: "Los apoyos sociales a los regímenes...", art. cit., p. 63. 
capacidad para movilizar a ingentes masas de población a través del liderazgo carismático de Mussolini. Sin embargo, considera que a sus reflexiones le falta comprobación empírica ${ }^{12}$. ¿De qué manera la dictadura mussoliniana - se pregunta el catedrático- logró concitar, si es que lo hizo, un sentimiento más o menos unánime de aprobación en torno a sus proyectos totalitarios? ${ }^{13}$.

Una respuesta a esta pregunta la podemos encontrar en la militarización de la educación y la politización de planes de estudios y libros de textos. Destaca la labor, por ejemplo, de la Gioventù Italiana del Littorio (GIL), dentro de la cual estaba integrada la Opera Nazionale Balilla, controlada por el PNF desde 1937 y encargada del adoctrinamiento de la juventud. La consolidación de organizaciones juveniles fascistas fue mayor en áreas industrializadas y septentrionales, y más relevante entre la clase media que en el mundo obrero. Ahora bien, la historiografia ha querido destacar organizaciones recreativas como la Opera Nazionale Dopolavoro, que ocuparán un papel singular en la atracción de las clases trabajadoras hacia el proyecto transformador y modernizador del régimen italiano. Es oportuno señalar el cambio que vivió la OND desde una institución destinada a informar al obrero de nuevas técnicas y mejoras tecnológicas a una organización recreativa que permitía al traba-

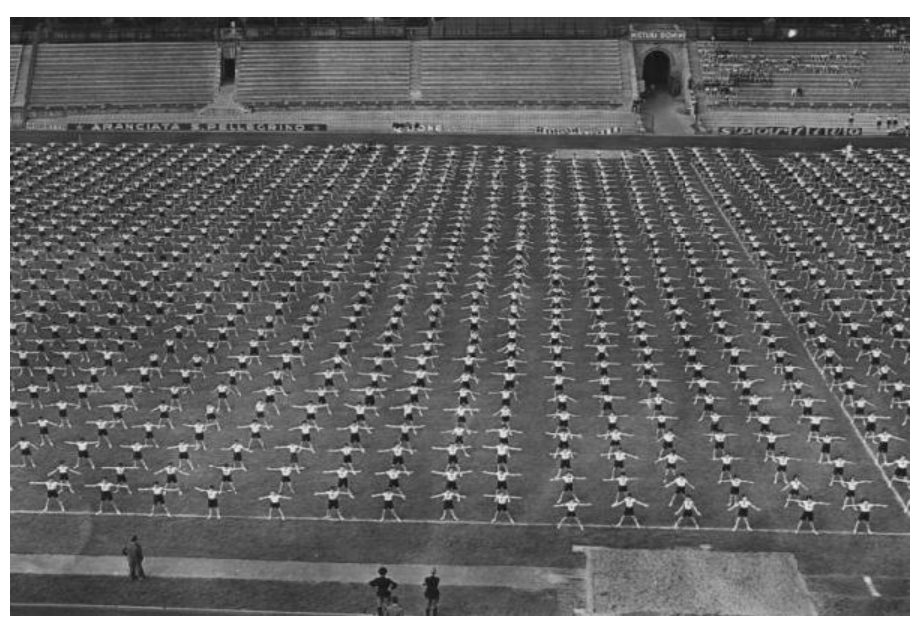
jador disfrutar de actividades deportivas y de ocio. Estos proyectos no proyectaban crear sujetos sumisos al régimen, sino conformar un consenso auténtico, una identificación real con el pensamiento fascista.

Imagen: Gioventù Italiana del Littorio, Milán (Licencia Wikipedia Commons).

Un estudio destacado es, por un lado, el análisis histórico oral y local publicado en la década de 1980 por parte de Luisa Passerini acerca de la clase obrera de Turín. Su obra constatará la capacidad de movilización de las masas de trabajadores hacia las instituciones sociales fascistas en detrimento de la izquierda politica. Muchos trabajadores con experiencia técnica (véase, por ejemplo, ingenieros, matemáticos, etc.) percibieron en el Partido Nacional Fascista (PNF) un espacio para explotar sus conocimientos, siendo compensado su trabajo con nuevas oportunidades económicas y ascensos laborales. Por otro lado, si queremos analizar en qué medida los dirigentes politicos controlaron el pensamiento del pueblo italiano y cómo fueron transformándose las actitudes populares desde 1930, es interesante el trabajo realizado por Simona Colarizi a principios de la década de 1990. Se hablaria de tres grandes fases en la evolución de dichas actitudes: una de represión institucional contra la oposición; otra segunda, iniciada en 1929, marcada por el conformismo y la

12 Ibid., p. 67.
13 Ibid., p. 68.

https://doi.org/10.53335/cliocanarias.2021.3.03

8/Cliocanarias, ISSN 2695-4494, n. ${ }^{\circ} 3$ (2021), pp. 1-29, La Laguna (Canarias) 
adaptación; y una tercera fase, a partir de 1943, donde la disconformidad ante el régimen se hizo más evidente. De esta manera el consentimiento se vería como una fina armonía entre la coacción y la persuasión. Asimismo, Patrizia Dogliani, a finales de la década de 1990, propuso la idea de una política contradictoria en la dictadura: la propaganda, orientada a atraer a más gente a la causa fascista, se ejercía a la par que la represión. De esta manera, la policía secreta fascista (OVRA) y el Tribunal Especial se erigirán como elementos coercitivos del nuevo régimen.

En el año 2014, Patrick Bernhard sacó a la luz un escrito donde reseña una serie de publicaciones pertenecientes a lo que denomina historiografia posrevisionista en algunos casos y antirrevisionista en otros. En primer lugar, comenta la obra de Maura E. Hametz titulada In the Name of Italy: Nation, Family and Patriotism in a Fascist Court, del año 2012. En ella, reseña Bernhard, la autora defiende al nacionalismo, al catolicismo, a los lazos regionales y a la familia como vehículos de identidad ${ }^{14}$ de la estructura ideológica fascista. La obra de Kate Ferris, Everyday life in fascist Venice, utiliza, como en el caso de Hametz, un ejemplo local para analizar la relación régimen-población; a diferencia de esta, Ferris muestra que el nacionalismo, el catolicismo, el militarismo y la tradición local fueron cooptados para servir a la ideología fascista ${ }^{15}$. El tercer libro comentado por Bernhard es Ordinary violence in Mussolini's Italy, publicado en 2010 por Michael R. Ebner. En él se incide en el aparato represivo y persecutorio del Estado italiano: se revela la condición o valor policial que puede suponer cualquier ciudadano, siendo en este caso la población un agente activo en la búsqueda y captura de enemigos del régimen (sin tener que ser, por ello, un fascista convencido). Asimismo, es mencionado Christopher Duggan y su obra Fascist Voices: an intimate history of Mussolini's Italy, donde lleva a cabo un análisis emocional de los italianos, subrayando que el culto a la personalidad que giraba en torno a la figura de Mussolini era considerablemente tenaz.

\section{La Alemania nazi}

\subsection{Resistencia y oposición}

Roberta Pergher reflexionaba en 2015 sobre la diferencia entre el régimen fascista italiano y el nacionalsocialista alemán: en torno al primero puede suscitarse un debate moral sobre posibles connotaciones positivas a la luz del apoyo popular y el consenso, algo que no ocurre en el segundo caso, en torno al que la posición moral es inequívoca ${ }^{16}$. Italia, para De Felice, se veía como un caso menor, si lo comparamos con Alemania. Sin embargo, este "blanqueo" de los crimenes fascistas italianos, afirma Pergher, ha sido denunciado por historiadores como Patrick Bernhard, quienes observan en ambos países estilos similares de gobierno, proyectos expansionistas similares, ideas raciales

\footnotetext{
${ }^{14}$ BERNHARD, Patrick: "Renarrating Italian Fascism: New Directions in the Historiography of a European Dictatorship", en Contemporary European History, n. ${ }^{\circ}$ 23, 2014, p. 155.

15 Ibid., p. 156.

16 PERGHER, Roberta: "The Ethics of Consent-Regime and People in the Historiographies of Fascist Italy and Nazi Germany", en Contemporary European History, n. ${ }^{\circ}$ 24, 2015, p. 311.
} 
similares y politicas de ocupación igualmente asesinas ${ }^{17}$. A pesar de ello, los diferentes contextos históricos en los que Hitler y Mussolini se alzaron con el poder y se consolidaron han sido origen de discrepancias en las historiografias nacionales acerca de la relación régimen-población. Pergher recuerda que Mussolini llegó al poder con poco apoyo popular y una buena cantidad de violencia y finalmente fue derrocado desde dentro; Hitler habia sido respaldado electoralmente y sus tropas siguieron luchando hasta que cuatro quintas partes del territorio alemán estaba en manos enemigas ${ }^{18}$.

En los años que siguieron a la Segunda Guerra Mundial, la consideración de la Alemania nazi como un Estado policial, donde la libertad ciudadana era sumamente reducida, era generalizada entre los historiadores. En 2011 Cobo Romero destacaba el "proyecto Baviera" como un pilar fundamental de los nuevos enfoques historiográficos desarrollados en los años setenta, realizándose de esta manera un estudio exhaustivo de las actitudes sociales de la población alemana frente el nazismo, en el que no solo señalaba las diversas actitudes de consenso hacia el nacionalsocialismo, sino que también advertía de la existencia de múltiples expresiones de disidencia y desencuentro entre, por ejemplo, determinados grupos sociales que diferian de la política ecoonómica nazi ${ }^{19}$. Esto último se puede observar, por ejemplo, en aquellas clases medias que tenían contactos comerciales con el mundo judío y no compartían los ataques que sufrían estos en sus negocios, concluyendo Longerich que cuanto más antisemitas eran las medidas adoptadas, menos dispuesto se mostraba el grueso de los alemanes a aprobarlas ${ }^{20}$. Por tanto, cabe destacar la dificultad que encontró el régimen a partir de 1933 para conseguir respaldo a sus politicas, ante la lealtad colectiva que guardaban millones de trabajadores a los ideales y principios de la socialdemocracia y el comunismo, y cuya expresión formal sólo podía quebrarse mediante el terror ${ }^{21}$. Campos se movió en la misma idea, considerando que si bien el régimen consiguió aislar, segmentar, las distintas experiencias y actitudes criticas individuales [...] no consiguió que desaparecieran [... $]^{22}$. Cobo Romero señala a Broszat como autor del concepto de Resistenz, haciendo referencia a todos aquellos obreros industriales que, influenciados por la ya mencionada socialdemocracia, no aceptaban integrarse en el nuevo orden implantado por los nazis: un rechazo que si bien no se hacia explicito mediante sonoras, rotundas y organizadas acciones colectivas de protesta, no por ello dejaba de revelarse a través de una silenciosa, descoordinada, subrepticia, pasiva y, en la mayoria de las ocasiones, individualizada contestación ${ }^{23}$.

\section{2. Los apoyos del Führer}

Frente al enfoque dado en el "proyecto Baviera", Robert Gellately o Eric A. Johnson serán algunos de los principales artífices de nuevas investigaciones

17 Ibid., p. 313.

18 Ibid., p. 310.

19 COBO ROMERO, Francisco: "Los apoyos sociales a los regimenes...", art. cit., p. 73.

20 EVANS, Richard: El Tercer Reich: en la historia y la memoria, Barcelona, Pasado \& Presente,

2015, p. 127.

${ }^{21}$ Ibid., p. 107.

${ }^{22}$ SAZ CAMPOS, Ismael: Fascismo y franquismo, Valencia, Universitat, 2004, p. 115.

${ }^{23}$ COBO ROMERO, Francisco: "Los apoyos sociales a los regimenes...", art. cit., p. 74. 
y estudios vertebrados en torno al papel desempeñado por los ciudadanos, que colaboraron con la Gestapo o las SS en la búsqueda y persecución de enemigos de la nación y disidentes; colaboración que en muchos casos les reportaba beneficios. Bien es cierto que, muchas veces, las denuncias de unos ciudadanos a otros respondian más a motivos personales que a determinadas actitudes hacia al régimen y sus politicas. En cualquier caso, autores como Ian Kershaw no dudan en señalar que el temor al bolchevismo y el predominio del antimarxismo entre las clases medias alemanas [...] constituyeron incuestionablemente una amplia base negativa sobre la que se sentó la popularidad de Hitler ${ }^{24}$. A finales del siglo Xx, Daniel Jonah Goldhagen publicaba la obra Los Verdugos Voluntarios de Hitler, originando un auténtico punto de inflexión en los estudios y análisis del Holocausto y la participación ciudadana del genocidio perpetrado por los nazis. Con gran repercusión mediática y académica, su tesis buscó demostrar cómo los alemanes corrientes colaboraron activa y voluntariamente con los miembros del NSDAP en el exterminio judio. Para Goldhagen, la cultura antisemita en Alemania circulaba mucho tiempo antes de la llegada del nacionalsocialismo; el ascenso de Hitler simplemente supuso un pequeño impulso a una sociedad que no comulgaba desde hacía tiempo con los principios morales occidentales. En los primeros años de gobierno nazi dificilmente se puede atribuir la violencia contra los judios a los miembros de las SA, como si el resto de la población no hubiera colaborado directa o indirectamente con ella. Por ejemplo, el escritor estadounidense menciona la "noche de los cristales rotos" o Kristallnacht (1938), en la que participaron alemanes "normales" de manera totalmente voluntaria y espontánea. Sin embargo, otros autores han criticado esta idea por su simpleza: existen otros factores a tener en cuenta a la hora de analizar la actitud ciudadana.

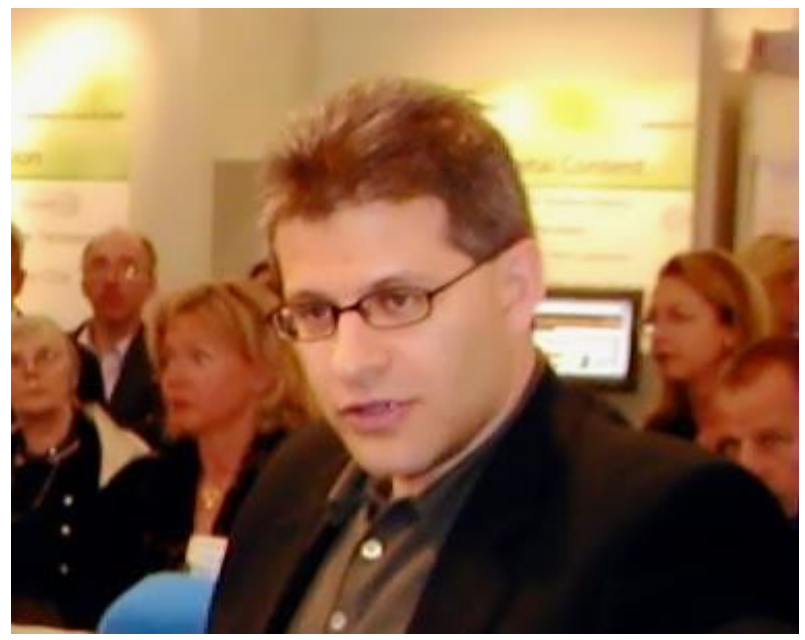

Imagen: Daniel Jonah Goldhagen. Sus tesis acerca del antisemitismo alemán causaron gran controversia (licencia Creative Commons).

Frente a Goldhagen, Gellately apuesta por la multicausalidad ante el consenso - no solo el antisemitismo como principal factor-, afirmando que este último tuvo al principio poca importancia [...], porque privar a los judios de sus medios de vida habría ido en perjuicio de la recuperación económica del

24 KERSHAW, Ian: El mito de Hitler. Imagen y realidad en el Tercer Reich, Barcelona, Paidós Ibérica, 2003, p. 326. 
pais [... $]^{25}$. Gellately asegura que, frente a la tesis de que el pueblo alemán desconocía la existencia de los campos de concentración, los medios de comunicación y propaganda ocuparon un papel significativo en la difusión pública de la labor realizada por la policía y los mencionados campos. A pesar de ese conocimiento, el favor generalizado hacia Hitler se vio refrendado a través de los plebiscitos realizados en 1933 (sobre la salida de Alemania de las Naciones Unidas) y 1934 (sobre la fusión de los cargos de canciller y presidente de la República), con un apoyo de más del 90 \% en el caso del primero y cercana a esa cifra en el caso del segundo. En el plebiscito de 1933 no debemos olvidar, eso sí, dos circunstancias fundamentales: el resto de partidos estaban ilegalizados y se produjeron casi tres millones de votos nulos que vienen a manifestar una cierta oposición pública a los nazis.

Al principio de la Segunda Guerra Mundial mucha gente que se había manifestado escéptica en un primer momento acabó apoyando al Führer por patriotismo o convencida por las primeras victorias ${ }^{26}$. Con el paso de los años, y a pesar de las sucesivas derrotas alemanas y la caida del optimismo general, los sondeos de opinión recogieron innumerables muestras de que la moral se mantenía firme, en el sentido de que muchos alemanes de todos los sectores sociales estaban dispuestos a seguir luchando 27 . En definitiva, el historiador Gellately llegó a considerar tres fases en las que se fue modificando la opinión popular respecto al nazismo. Una primera se produciria desde la llegada de Hitler al poder en 1933 hasta el inicio de la Segunda Guerra Mundial en 1939, donde el ciudadano alemán que no representaba una amenaza política o social encontró estabilidad económica y seguridad a cambio de renunciar a diversas libertades; en esta etapa el uso del terror no fue tan generalizado ante la falta de una resistencia organizada, la preocupación de Hitler por integrar y acomodar a la población al nuevo régimen y la aceptación de la faceta represiva de este por la ciudadanía. Es más, el autor pone énfasis en la labor ejercida por la Kripo, ya que los buenos ciudadanos agradecian que la policia pusiera a buen recaudo a los individuos normalmente considerados criminales [... $]^{28}$. La represión se dio de forma muy concreta y selectiva, el aparato de propaganda buscó "agradar" y no "imponer" y los logros económicos alcanzados por Hitler, así como las primeras anexiones territoriales, hicieron crecer el número de adeptos. La segunda fase, iniciada en 1939, no presenció una disminución del apoyo social ya que, aunque había discrepancias con ciertas politicas, el régimen no tuvo la menor dificultad para conseguir que la población denunciara las supuestas infracciones de la normativa racista ${ }^{29}$. La mayoria de los presos en campos de concentración será de origen extranjero, así que los "buenos ciudadanos" no tenian que temer. Por último, en los postreros meses del Tercer Reich todavia habia alemanes optimistas que se negaban a rendirse y traicionar a su líder a costa de la victoria soviética. Aún así, como afirma Kershaw, en este período final del nacionalsocialismo la represión terrorista vivió una

25 GELLATELY, Robert: No sólo Hitler. La Alemania nazi entre la coacción y el consentimiento, Barcelona, Crítica, 2003, p. 17.

26 Ibid., p. 303.

27 Ibid., p. 339.

28 Ibid., p. 345.

29 Ibid., p. 350. 
feroz escalada a medida que la fuerza aglutinante de la popularidad de Hitler iba debilitándose y derrumbándose ${ }^{30}$.

\subsection{La gran obra social}

Socavado el concepto de Resistenz en la década de los noventa, se señalará que el Tercer Reich había conseguido, parcialmente, desintegrar las identidades colectivas y solidarias de los obreros industriales cualificados anteriormen te mencionados, así como sus prácticas conflictivas, facilitando su integración en el organigrama politico y social del nuevo régimen. Se había conseguido a través de nuevas estrategias laborales, encauzadas a partir de la industria armamentística y la difusión del consumo de masas (con el correspondiente disfrute de actividades de ocio y recreo). En este sentido, ocupará un papel relevante el Frente Alemán del Trabajo (DAF), que otorgará a los obreros una serie de nuevos valores de producción racionalizados donde se potenciará el bienestar y las cualidades individuales y se ensalzará la tarea bien hecha al servicio de la comunidad nacional ${ }^{31}$.

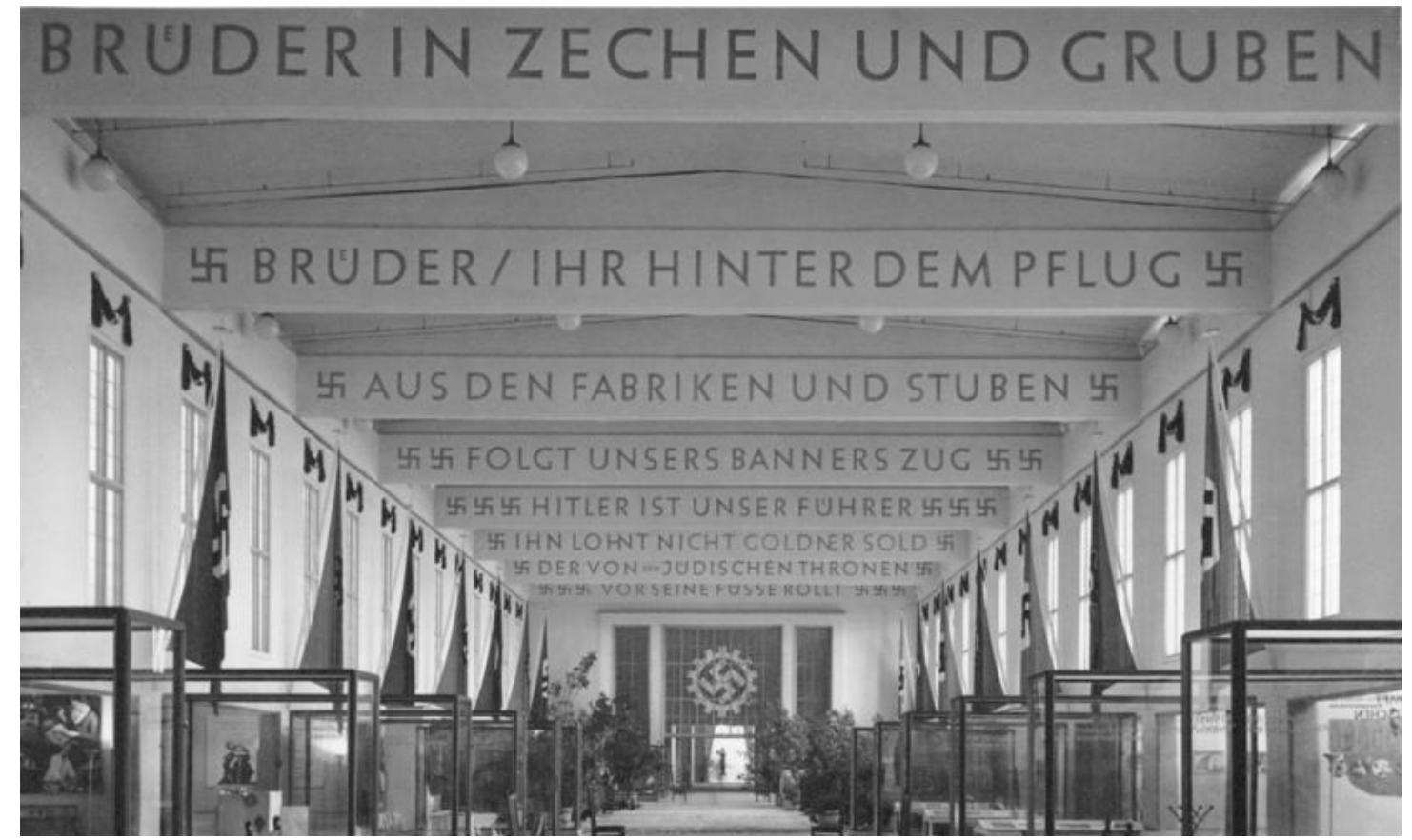

Imagen: Exposición nacionalsocialista organizada por el Frente Alemán del Trabajo (1938) (Licencia Creative Commons).

También se ha señalado que el régimen nazi se propuso la fidelidad social y el sentimiento de unidad nacional a través de diversas organizaciones de beneficencia en las que participara la gente joven, como el caso del Nationalsozialistische Volkswohlfahrt, cuyo equivalente italiano era el Ente Opere Assistenziali. Sus campañas de Auxilio de Invierno (Winterhilfwerk) consistirán en la recolecta anual de marcos para ayudar a los más desfavorecidos; quienes hacian donativos portaban una serie de insignias que contribuian a ensalzar la solidaridad y participación colectiva. No alistarse en las Juventudes Hitlerianas podía suponer, por ejemplo, como elemento de coerción, no recibir el

30 KERSHAW, Ian: El mito de Hitler..., op. cit., p. 332.

31 COBO ROMERO, Francisco: "Los apoyos sociales a los regimenes...", art. cit., p. 76. 
certificado de fin de escolaridad obligatoria al graduarse, lo que negaba a los jóvenes toda esperanza de formarse como aprendices o encontrar trabajo ${ }^{32}$.

Los recursos materiales y económicos obtenidos en las campañas bélicas a través de una vasta gama de medidas de ingeniería financiera y presupuestaria $^{33}$ permitirian al ciudadano alemán disfrutar de un cierto nivel de vida y convencerlo de los beneficios de las politicas expansionistas. Los jerarcas nazis cumplian asi sus promesas de campaña para reconducir la economía de Alemania y, a través de programas como Kraft durch Freude ("Fuerza a través de la alegria"), que ponía a disposición de la clase obrera diversas actividades turísticas y de ocio a las que nunca habian tenido acceso y rompia de esa manera las barreras de clase, se ganó el apoyo de las masas.

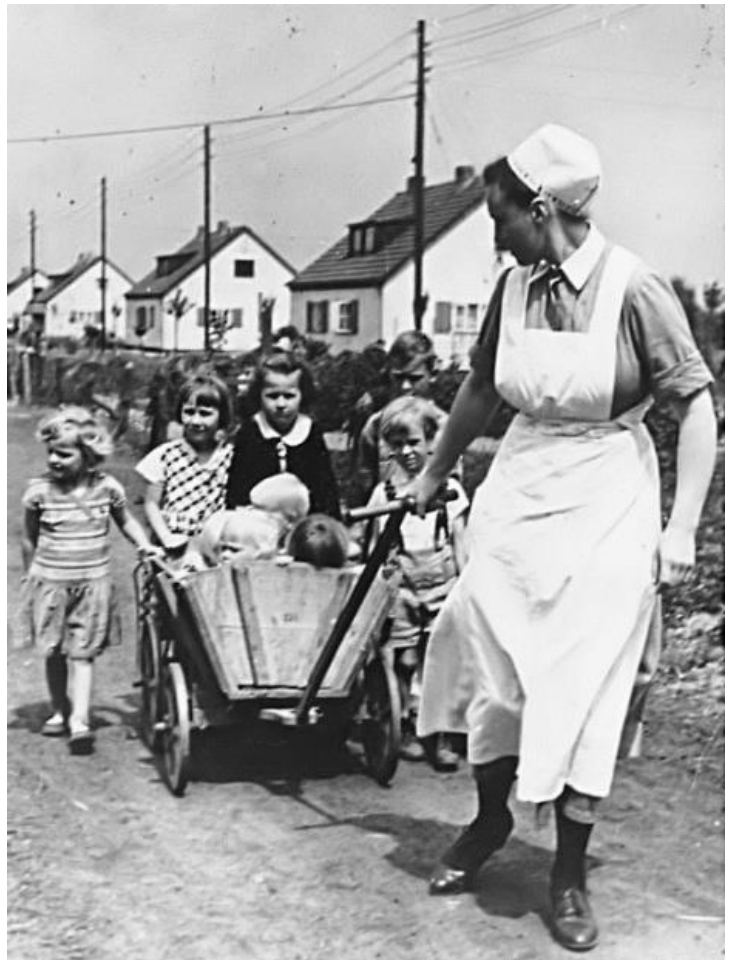

Imagen: Enfermera del Nationalsozialistiche Volkswohlfahrt con unos niños (1943) (Licencia Creative Commons)

A pesar de constituirse organizaciones similares a Kraft durch Freude - tales como Opera Nazionale Dopolavoro, comentado en apartados anteriores-, algunos autores señalan que Mussolini no tuvo la capacidad de garantizar una vida más confortable a los italianos. En definitiva, Hitler empleó una serie de incentivos o remuneraciones para atraer al pueblo a su causa; la mayoría de la población agradecía a los nazis, en palabras de Fritzsche, el haber devuelto a la gente al trabajo, el fomentar un mayor sentido de igualdad social con acciones politicas simbólicas [...], el haber restaurado el prestigio internacional de Alema$n_{i a^{34}}$. Además, frente a las teorias de Fritzsche y el papel otorgado a la Volksgemeinschaft ("comunidad popular") como herramienta de homogeneización social y racial e identificación nacional, visiones escépticas con sus planteamientos afirmarán que el campesinado del mundo rural, especialmente a partir del inicio de la Segunda Guerra Mundial, se revelará contrario a renunciar a su libre modo de supervivencia económica y a asumir la doctrina ideológica nazi. Fritzsche consideraba que muchos alemanes abrazaron el nacionalsocialismo porque parecia ofrecer una versión nueva y mejorada de la vida nacional, ya que la mayoria de los alemanes preferia el futuro nazi al pasado de Weimar, sin que eso tuviera necesariamente que implicar una coincidencia con todos los puntos de la politica nazi, y menos con la deportación y asesinato de los judios alema$n^{3}{ }^{35}$. En otras palabras, Fritzsche no termina de comulgar del todo con un

32 EVANS, Richard: El Tercer Reich..., op. cit., p. 115.

33 COBO ROMERO, Francisco: "Los apoyos sociales a los regimenes...", art. cit., p. 80.

34 FRITZSCHE, Peter: Vida y muerte en el Tercer Reich, Barcelona, Crítica, 2008, p. 68.

35 Ibid., p. 43. 
"giro voluntarista", al entender que la relación nazi-alemán no fue uniforme en el tiempo; explora tanto las limitaciones de la "nazificación" como sus éxitos $^{36}$. Si bien los soldados de la Wehrmacht, por ejemplo, experimentaron un proceso de radicalización, en el que su compromiso en relación con el nazismo y la figura de Hitler era inquebrantable, la evolución de la guerra demostró que cuanto mayor era la certeza de la derrota, más se intensificó el miedo de la ciudadanía a la animadversión de los Aliados [... ${ }^{37}$. Es más, la interferencia de los nazis en la vida cotidiana acabó decepcionando a muchos de los que se habian inclinado hacia el movimiento.

\subsection{Gellately y Evans: distintas prioridades analiticas}

Richard J. Evans, a diferencia del académico canadiense Robert Gellately, no infravaloraba la violencia cometida contra los representantes politicos de la clase obrera alemana, principales víctimas de la coerción nazi desde 1933. En este sentido, Evans juzgaba un error catalogar a los comunistas como "marginados sociales" - a los que se atribuía casi exclusivamente la violencia-, dada su alta representación electoral. Asimismo, critica de Gellately el hecho de no dar importancia a la represión ejercida contra los socialdemócratas, incluso antes de 1933. Evans afirmaba que el ascenso al poder del Führer no había sido precisamente legitimo, pues la ley orgánica que brindó buena parte de los poderes legislativos de Hitler fue aprobada de manera ilegal $^{38}$. Incluso llegaba a enumerar las diversas artimañas que los nazis utilizaban para inclinar a su favor los resultados electorales de distintos plebiscitos llevados a cabo durante 1934: manipulaciones ejecutadas por los camisas pardas a través del señalamiento del discrepante, el arresto de los opositores o la preparación previa del voto. Además, argüía que, frente a la clase obrera, las clases medias y el campesinado se mostraron más dispuestas a dar oídos al mensaje nacionalsocialista, dado el temor que profesaba al comunismo ${ }^{39}$. Profundizando en el tema de la violencia, Richard Evans discrepaba mucho sobre el hecho de reducir esta a un pequeño sector de la población despreciado por la mayoría. No solo carga contra Gellately, sino también contra autores de la talla de Hans-Ulrich Wehler, que reducian la represión nazi a la Gestapo y los campos de concentración. Para Evans, la ley era el instrumento principal del terror, ya que en los años treinta la represión política radicaba especialmente en los tribunales ordinarios y las prisiones $y$ penitenciarias estatales 40 . De esta manera, diversos decretos y normas aprobados a partir de1933 pretendieron eliminar cualquier manifestación de disensión y oposición o cualquier atisbo de traición, complot u organización no permitida. La consecuencia no tenía por qué ser la llegada a un campo de concentración, sino a una cárcel estatal. Gellately, representante de un "giro voluntarista" en la historiografia del fascismo, no sabía dar respuesta a la existencia de un organigrama de terror en el régimen nazi si, como afirmaba, no fue tan necesaria la represión del pueblo. Evans, al igual que con Gellately,

\footnotetext{
36 EVANS, Richard: El Tercer Reich..., op. cit., p. 138.

37 Ibid., p. 142.

38 Ibid., p. 104

39 Ibid., p. 107.

40 Ibid., p. 112.
} 
cargaba contra Peter Fritzsche por su infravaloración de la coacción y la intimidación (a pesar de no contemplarlo un defensor radical del "giro voluntarista"). En primer lugar, estimaba que Fritzsche no ofrecía ninguna prueba concreta de que la población de Alemania tratara de forma activa de acomodarse a los propósitos del régimen ${ }^{41}$. En segundo lugar afirmaba que, a pesar de ser consciente de la violencia ejercida por los nazis a lo largo de 1933, incurría como Gellatelly en el error de obviar la acción de los tribunales y del sistema judicial regular como factor claves en la reducción del número de reclusos en los ya mencionados campos de concentración. Las fuentes primarias - diarios y cartas - que empleaba Fritzsche en su obra quizá no hicieran mención al temor que podian suscitar el castigo o la amenaza, pero este hecho acredita que [...] sus autores debieron de actuar con no poca cautela a la hora de expresar nada que pudiera comprometerles [... $]^{42}$.

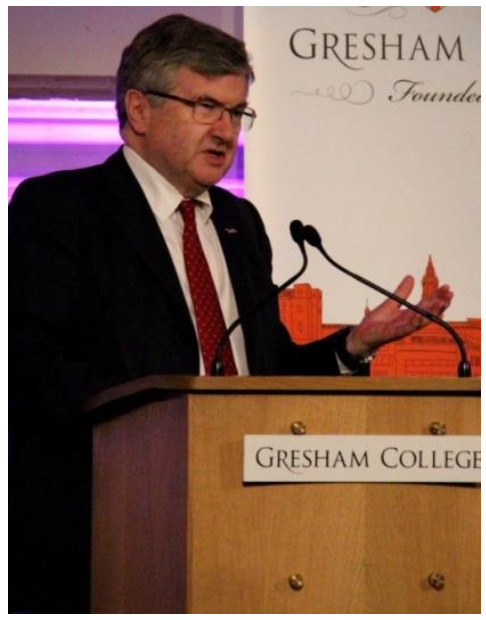

Imagen: el profesor y experto del Tercer Reich Richard J. Evans durante una conferencia en 2015 (licencia Creative Commons).

\subsection{La conformación de la Volksgemeinschaft}

Es de vital importancia el papel de la educación como vehículo de expansión ideológica, especialmente entre los jóvenes. Este sector de la población es, sin duda alguna, el más manipulable, pues en muchos casos no han desarrollado una conciencia crítica ni una escala de valores suficientemente sólida para no ceder ante la ingente cantidad de propaganda y adoctrinamiento del régimen. Así lo recogen las investigaciones de Johnson y Reuband, que afirman que el $62 \%$ de los ciudadanos encuestados nacidos en Berlín entre 1923 y 1928 admitia haber mantenido una postura positiva o principalmente positiva sobre el nacionalsocialismo, a diferencia de generaciones anteriores ${ }^{43}$. De gran repercusión será la realización del famoso documental El triunfo de la voluntad, donde se representará el congreso del Partido Nacionalsocialista celebrado en Núremberg en 1934. Llama la atención también, por ejemplo, el uso en todos los ámbitos de la vida cotidiana del saludo nazi Heil Hitler! que, de alguna manera, al sustituir a otras expresiones como "buenos dias", se convirtió en un signo externo público de apoyo al régimen ${ }^{44}$ : el riesgo a represalias invitaba

41 Ibid., p. 139.

42 Ibid., pp. 141-142.

43 Ibid., p. 119.

44 Ibid., p. 153. 
a responder al saludo, dando la impresión externa de que existía un consenso generalizado en torno al nazismo.

Con todo ello, se ha de incidir en la creación simbólica de una comunidad popular o Volksgemeinschaft, sustentada en la idea de una identidad nacional a la que solo podian suscribirse determinadas personas de pureza aria y de utilidad productiva (esto descartaba, entre otros, a los enfermos mentales y discapacitados). Por tanto, la Volksgemeinschaft generaba dos clases de emociones: por un lado, una sensación de pertenencia y objetivo común entre sus miembros; y, por otro, un sentimiento de distinción, de separación entre los individuos vinculados a la comunidad y las personas ajenas a ella. El "orgullo" de formar parte de esa colectividad era difundido a través de los medios de comunicación y todos los elementos propagandísticos posibles, desde la arquitectura hasta el cine: se creó así una auténtica banda sonora y escenografia visual en torno al régimen, haciendo partícipe al pueblo, otorgándole un rol y sentir protagonista en la historia de Alemania. Se conseguía de esta manera convencer a la ciudadanía de que aquellos que no cumplian ciertos requisitos de raza y mentalidad no serian nunca integrados en la Volksgemeinschaft. A esta idea Saz Campos añadia que la incuestionable modernidad de la politica social nazi y la poderosa capacidad de atracción del mito - parcialmente realizado- de la comunidad nacional contribuyeron a la disolución de identidades como las de clase o estatus, lo que explica la amplitud de los apoyos sociales al régimen 45 . Ahora bien, Fritzsche argumentaba que la Volksgemeinschaft no había sido un invento nazi, puesto que desde el inicio de la Primera Guerra Mundial en 1914 la comunidad del pueblo habia representado la reconciliación de los alemanes, durante tanto tiempo divididos por razones de clase, región y religión ${ }^{46}$. Al mismo tiempo, este espíritu de fortaleza colectiva fue empleado por los nazis años después, utilizando los acontecimientos desencadenados en Alemania tras el fin del conflicto bélico: 1914 representaba la renovación y la vida, mientras que 1918 era la amenaza de la revolución, el caos y, en última instancia, la muerte 47.

Por último, el historiador alemán Götz Aly consideraba que el régimen nacionalsocialista se había preocupado por garantizar el bienestar económico y social de sus ciudadanos. Con el tiempo, la población fue sintiendo una sensación de seguridad y confort ante las mejoras laborales y fiscales que introdujeron los nazis. Para preservar el nivel de vida del pueblo alemán fue necesario llevar a cabo una política de expolio y rapiña de los recursos de los territorios que se iban ocupando; así, los gastos derivados de la guerra no dañaban tanto la economía del país. Los judios, en este sentido, fueron victimas de expropiaciones, cuyos beneficios se destinaban a los alemanes arios. Sin embargo, los judios ni eran tantos ni eran lo suficientemente ricos para aumentar la calidad de vida de la nación. Además, si los factores materiales y el bienestar económico habian cimentado la lealtad del alemán al nazismo, cabria haber esperado una desolación mayor ante su caída.

\footnotetext{
${ }^{45}$ SAZ CAMPOS, Ismael: Fascismo y..., op. cit., p. 115.

${ }^{46}$ FRITZSCHE, Peter: Vida y muerte..., op. cit., p. 45.

47 Ibid., p. 45.
} 


\section{E1 franquismo}

\subsection{La cultura de la victoria: vencedores y vencidos}

Se han definido una serie de factores que se entremezclaron en la conformación de un consenso durante el franquismo: la génesis cultural que vertebró la movilización politica en 1936, el discurso legitimador de los "alzados", la politica de recompensas hacia los apoyos recibidos por estos últimos y la corrupción o la extensa represión. Entender las actitudes politicas de la población española durante el llamado "primer franquismo" es comprender el papel que jugó la represión en los años inmediatamente posteriores a la guerra civil. Cárcel o muerte se convirtieron en las expectativas que ofrecía adoptar una postura hostil al nuevo régimen. Molinero e Ysàs pensaban que la dictadura franquista se había erigido, particularmente durante sus primeros momentos de consolidación, en torno al empleo de la violencia politica, con la creación de un vasto aparato represivo destinado a neutralizar y a destruir cualquier ameaza del Nuevo Estado ${ }^{48}$. Otros investigadores afirman que la perdurabilidad del régimen franquista en el tiempo no pudo basarse únicamente en la represión que, aunque fundamental y decisiva, hubo de complementarse con una serie de apoyos sociales e institucionales y un cierto grado de aceptación ciudadana. ¿Dónde nacía esta aceptación?

Es fundamental señalar el establecimiento de una distinción entre vencedores y vencidos, asumiendo la existencia de grupos populares en ambos bandos y, por tanto, concluyendo que esta división se superponía a las de clase 49 . Los "vencidos", identificados y perseguidos de forma sistemática, manifestaron su hostilidad al régimen, mientras que aquellos que habian simpatizado o colaborado con los "vencedores", se declararian partidarios de aquel; algo lógico, si tenemos en cuenta los beneficios que les reportaba su condición de victoriosos, como podía ser la obtención de pensiones, viviendas o cargos públicos. Esto último, por ejemplo, lo vemos reflejado en la composición provincial de ayuntamientos, diputaciones y órganos de poder, desde donde estos "vencedores" se encargaban de delatar a los enemigos de la patria, exigir el castigo de quienes consideraban culpables de las muertes de sus familiares o solicitar al Estado que honrara la memoria de los caidos por la causa rebelde ${ }^{50}$. Los vencedores se convirtieron, por tanto, en los encargados de construir el régimen "desde abajo". Estos, en palabras de Miguel Ángel del Arco Blanco, estaban unidos por un corpus de ideas que justificaban la represión $y$, en algunos casos, les hacian participar en el ejercicio de la violencia y en el control social, fortaleciendo su identidad de vencedores y vigorizando al régimen franquista del que eran parte ${ }^{51}$.

Las Comisiones Provinciales de Incautación de Bienes, el Cuerpo de Investigación y Vigilancia y el Servicio de Investigación de Falange se erigirán

\footnotetext{
48 MOLINERO, Carmen, y Pere YSÀS: "La Historia social de la época franquista: una aproximación", en Historia Social, n. ${ }^{\circ}$ 30, 1998, p. 134.

49 SAZ CAMPOS, Ismael: Fascismo y..., op. cit., p. 189.

50 HERNÁNDEZ BURGOS, Claudio: "Más allá del consenso...", art. cit., p. 94.

51 DEL ARCO BLANCO, Miguel Ángel: «El secreto del consenso en el régimen franquista: cultura de la violencia, represión y hambre", en Ayer, n. ${ }^{\circ}$ 76, 2009, p. 269.
} 
como instituciones del Nuevo Estado destinadas a la represión y en las que participaría "gente corriente". La primera, dedicada desde 1937 a la confiscación de las propiedades de aquellos individuos que, en territorio conquistado, perjudicaran la labor del Movimiento Nacional, no podría haberse realizado sin la colaboración ciudadana en la elaboración de inventarios o en la tasación de bienes. La distribución de esas propiedades requisadas entre distintos grupos sociales (como, por ejemplo, comunidades religiosas afectadas por las oleadas anticlericales durante el Frente Popular) generó un apoyo social fundamental en la supervivencia del Nuevo Estado. La adhesión a estas organizaciones respondía en muchos casos a las consecuencias derivadas de la Guerra Civil que generaron ansias de justicia $y$ de compromiso politico que activaron actitudes enérgicas contra los republicanos ${ }^{52}$.

Las denuncias llevadas a cabo por parte de ciudadanos de a pie contra vecinos de idelogía contraria se verian de esta manera $-\mathrm{y}$ sin tener en cuenta los casos de individuos guiados por la coacción- como una compensación a sus sufrimientos vividos durante el conflicto y como una manifestación del éxito de la "cultura de la victoria", base de la división del país entre "buenos" y "malos", entre "vencedores" y "vencidos". Existía un escaso interés por parte del régimen en buscar la reconciliación; se pretendia, pues, la reintegración de los derrotados y su reeducación en valores católicos y conservadores. La necesaria justicia de Franco unirá a hombres y mujeres en la venganza de sus mártires y la limpieza de los enemigos de España. La Guerra Civil se vería como un acontecimiento palingenésico y sanador del cuerpo de la nación donde el enfrentamiento se convertiría en una fuerza creadora ${ }^{53}$ y la visión de Cruzada del conflicto ayudaría a construir nuevas mitologías, ritos y símbolos con el fin de ganar adeptos en la zona nacionalista. Alonso Ibarra definiría esta idea como la construcción de una narrativa sobre la guerra en la que primaba la desnacionalización del enemigo - extranjerizado, rusificado- y la renacionalización del conjunto de la sociedad española en clave católica, centralista y contrarrevolucionaria ${ }^{54}$.

\subsection{Zonas grises: apatía, apoliticismo, indiferencia, pasividad}

Frente a esta dicotomia entre vencedores y vencidos, entre apoyo inquebrantable y oposición militante, existian también individuos que optaban por la neutralidad, la indiferencia, la aceptación del régimen como un mal menor ante el deseo de no volver a experimentar episodios de violencia; aquellos que ni disfrutaron de los beneficios de la victoria ni de las consecuencias de la derrota. Podian existir personas con actitudes algo ambiguas que no llevaban a cabo una oposición o resistencia activa, pero que al mismo tiempo, en un deseo de reconciliación, no tenían por qué colaborar con la política oficial, pudiendo incluso llegar a ayudar, solidarizarse o proteger a algún miembro del bando republicano. En cualquier caso, la hostilidad hacia el régimen era

52 DEL ARCO BLANCO, Miguel Ángel, y Peter ANDERSON: "Construyendo la dictadura y castigando a sus enemigos. Represión y apoyos sociales del Franquismo (1936-1951)", en Historia Social, n. ${ }^{\circ} 71,2011$, p. 131.

53 DEL ARCO BLANCO, Miguel Ángel: "El secreto del consenso...», art. cit., p. 253.

54 ALONSO IBARRA, Miguel: "Los limites del fascismo en España. Un recorrido crítico por conceptos, interpretaciones y debates de la historiografia reciente sobre el Franquismo", en Studia Historica: Historia contemporánea, n. ${ }^{\circ}$ 35, 2017, p. 149. 
secundaria o minoritaria en comparación con la pasividad; pasividad que respondia, en primer lugar, al miedo o la represión, que tuvo efectos paralizantes y definitivos sobre la mayoría de la población ${ }^{55}$, pero también al prioritario objetivo de la supervivencia diaria. No solo se trataba de eliminar al enemigo político, sino también de disuadir y prevenir a aquellos que adoptaran actitudes y conductas inadecuadas. Sobre este tema el historiador Sevillano Calero opinaba que si bien no hubo una "adhesión entusiasta", existió una pasividad general en la sociedad. Este apoliticismo tuvo su origen en la represión y el miedo, las consecuencias de la economía en la población (con los efectos del hambre y el cansancio después de la guerra civil, y la mejora del nivel de vida a lo largo de la década de 1950) y la labor de la Iglesia católica, el Ejército y la Falange. Gracias a ello, continúa el autor, el nuevo Estado franquista no solo utilizó la violencia política, sino que penetró en la sociedad a través de la elaboración de una ideología5.

Antonio Cazorla apuntaba que reducir la represión franquista posterior a la guerra civil al distanciamiento generado entre la dictadura y los grupos sociales derrotados sería minusvalorar su capacidad para originar una ruptura entre una minoria opositora militante dispuesta a sufrirla y los antiguos defensores del Frente Popular, cuyas actitudes iban desde la apatía politica y el conformismo a la acomodación, pasando por la protesta individual ${ }^{57}$. En el mundo universitario, considera el catedrático andaluz, la apatía y despolitización que experimentaron la mayoría de estudiantes demuestra el fracaso de la socialización politica de la juventud en el franquismo58. Como bien recoge Hernández Burgos, los fuertes deseos de llevar una existencia centrada en la vida familiar y en el desempeño de sus trabajos fomentaron la desmovilización social y el rechazo a lo político ${ }^{59}$. El desapego de la población hacia los partidos, afirma Cazorla, explicaría cómo Falange a partir de 1945 pasó a un segundo plano con la facilidad que le permitía la escasa movilización social que geneeraba. El autor sopesaba que la historiografia española había indagado muy poco en conocer en qué medida y a quién merecía la pena el riesgo de sufrir la represión o de comenzar una segunda fase de la guerra civil [...] frente a la certeza de vivir en paz, por muy miserable que esta fuera, bajo el franquismo ${ }^{60}$. Un análisis sobre la opinión popular bajo la dictadura merece reparar, tal y como afirma el historiador almeriense, en la ausencia en la población española de perspectivas de un futuro esperanzador de libertad a corto plazo, teniendo en cuenta la actitud no intervencionista exhibida por las potencias aliadas victoriosas tras la Segunda Guerra Mundial. En esta línea, Molinero e Ysàs también apuntan que muchas personas valoraron más la seguridad que ofrecía el franquismo en la defensa de sus intereses esenciales que un futuro incierto que provocaba desconfianzas $y$ temores $^{61}$. La población perteneciente a es-

55 SAZ CAMPOS, Ismael: Fascismo y..., op. cit., p. 193.

56 SEVILLANO CALERO, Francisco: "Consenso y violencia en el "nuevo estado" franquista: historia de las actitudes cotidianas", en Historia Social, n. ${ }^{\circ}$ 46, 2003, p. 162.

57 CAZORLA, Antonio: "Sobre el primer franquismo y la extensión de su apoyo popular, en Historia y politica: ideas, procesos y movimientos sociales, n. ${ }^{\circ} 8,2002$, p. 316.

58 Ibid., p. 163.

59 HERNÁNDEZ BURGOS, Claudio: "Más allá del consenso...», art. cit., p. 95.

60 CAZORLA, Antonio: "Sobre el primer franquismo...", art. cit., p. 316.

${ }^{61}$ MOLINERO, Carmen, y Pere YSÀS: "La Historia social...", art. cit., p. 137. 
tas "zonas grises", en definitiva, se habituó a la falta de libertad y se centró en intentar, en la medida de lo posible, volver a su antigua "normalidad".

El optimismo de los españoles y su apoyo a Franco empezará a crecer desde los años cincuenta, momento de la rehabilitación del régimen a nivel internacional gracias a los acuerdos con el Vaticano y Estados Unidos. Será a partir de la década de los sesenta cuando la dictadura, aupada por su crecimiento económico, empleó las armas de propaganda necesarias para presentar ante los españoles las favorables consecuencias de la paz duradera en su bienestar social y poder adquisitivo. Debemos advertir que, frente a Mussolini y Hitler, cuya popularidad comenzó a descender a partir de los primeras grandes derrotas en la Segunda Guerra Mundial, la negación de España a entrar "oficialmente" en el conflicto internacional junto a las potencias del Eje (y destacando la propaganda del régimen la tenacidad de Franco en la famosa entrevista de Hendaya entre el Caudillo y el Führer), aumentó el prestigio del dictador español. Además, la responsabilidad de las miserias que vivía la población recaía sobre otros personajes como Serrano Suñer, otras instituciones como Falange e incluso otras épocas como la II República, siendo objeto Franco de un menor señalamiento popular gracias a los mecanismos de propaganda.

Imagen: El jefe de Estado de España, Francisco Franco, y el presidente de EE. UU., Dwight Eisenhower, en la base estadounidense de Torrejón (1959). Los pactos con el país norteamericano ayudaron a mejorar la imagen del dictador ante su pueblo. (Licencia Wikipedia Commons).

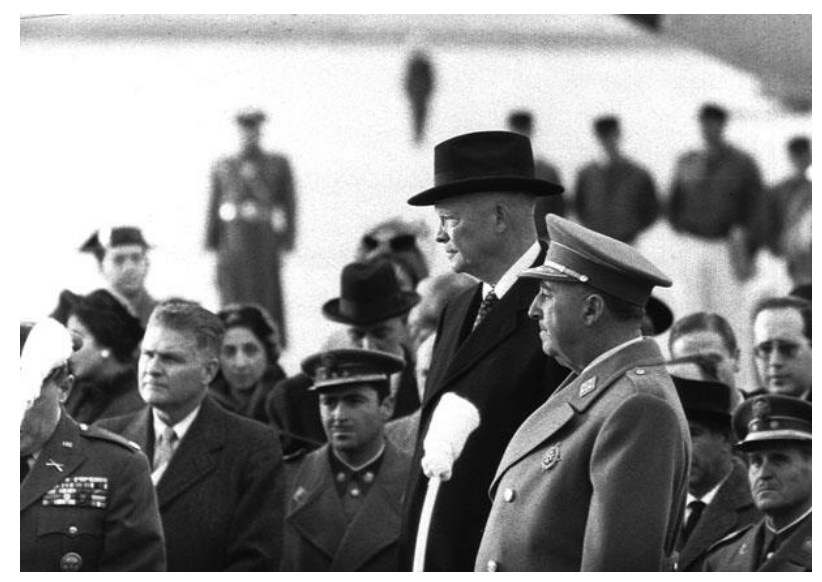

El rechazo europeo a la entrada de España en la ONU tras finalizar el conflicto internacional, paradójicamente, fortaleció la dictadura: la población se vio castigada por aquella medida, fuese afecta o no al régimen, resaltando la culpabilidad de las potencias extranjeras y alabando el papel de Franco en la defensa de su dignidad y la soberania nacional de España. La propaganda jugó un papel fundamental en la exaltación de la figura del dictador como un ser providencial, salvador de España del comunismo y de la disgregación de la patria y, al mismo tiempo, alababa su politica social centrada en la consecución de la justicia social, el orden y la paz ${ }^{62}$. Franco se erigió como el artífice de la superación del aislamiento y de la legitimación de su régimen por las potencias europeas. La educación y la moral cristiana se convertirán en base del adoctrinamiento y de la formación de los españoles. La primera se convirtió en un medio de transmisión de los valores morales e ideológicos del régimen a las nuevas generaciones, sustentados en los principios del nacionalcatoli-

62 MOLINERO, Carmen: La captación de masas: politica social y propaganda en el régimen franquista, Madrid, Cátedra, 2005, p. 42. 
cismo; a través de la segunda se consolidó un discurso ultracatólico defensor de valores tradicionales. El cumplimiento de estos preceptos morales formó parte de la vida cotidiana e íntima de la población.

\subsection{La actitud de los grupos sociales}

Los discursos posbélicos empleados por el bando nacional calaron entre las clases altas, las clases medias conservadoras y el campesinado familiar, que habian visto amenazado su estilo de vida ante las pretensiones republicanas. Hernández Burgos afirmaba que el franquismo supo explotar las simpatias que durante la guerra había engendrado en determinados grupos sociales su discurso nacionalista y católico. Por un lado, su concepción de una nación natural, eterna y exclusiva y su deseo de otorgar a España el papel internacional que le correspondía complacía a la derecha española más reaccionaria. Por otro, la empresa recatolizadora satisfizo los anhelos y esperanzas de muchos católicos españoles que percibian al nuevo régimen como una salvaguarda de sus creencias ${ }^{63}$. Ser español y ser católico se concebía, para algunos sectores sociales, como dos principios inseparables. En la retaguardia rebelde los soldados llevaban noticias acerca de la destrucción, por parte del bando republicano, de esculturas católicas, la colectivización de propiedades o la ejecución de diversos asesinatos; noticias que, reales o manipuladas, calaban entre la población.

Tal y como recogen Molinero e Ysàs, las clases burguesas y los grandes propietarios agrarios se posicionaron a favor del nuevo régimen, habiéndose sentido amenazados por el caos y la conflictividad en el caso del primer grupo, y hostigados por las políticas republicanas y el ascenso del movimiento obrero y campesino en el caso del segundo. No dudan en señalar que, por ejemplo, la burguesía industrial catalana se inclinó a favor del régimen, traumatizada por la experiencia colectivizadora y por la persecución sufrida64. En otras palabras, el apoyo se basaba en un factor económico más que en una cuestión política e ideológica. A aquellos productores de bienes de consumo que dependian del comercio exterior para adquirir materias primas, energia o maquinaria, no les complacía, como es obvio, la política autárquica de los primeros años del régimen. La llegada de los tecnócratas, el auge económico y la industrialización de los años sesenta garantizaba, para las clases burguesas, una motivación que iba más allá del simple "paz y orden". La conflictividad en esta década sería protagonizada por los sectores más "jóvenes y dinámicos", especialmente dentro del mundo industrial.

En cuanto a las clases medias, sostienen Molinero e Ysàs, el apoyo hacia el régimen durante sus primeros años fue mayor en las áreas interiores, donde la mentalidad conservadora, la influencia católica, los ecos fascistas ante los que se sentian atraídos los más jóvenes y los beneficios que implicaba la condición de "vencedores" fueron factores determinantes. El rechazo y la hostilidad pasiva vendrán de aquellos sectores vinculados a las tradiciones politicas

${ }^{63}$ HERNÁNDEZ BURGOS, Claudio: Franquismo a ras de suelo. Zonas grises, apoyos sociales y actitudes durante la dictadura: 1936-1976, Granada, Editorial de la Universidad de Granada, 2013, p. 115.

${ }^{64}$ MOLINERO, Carmen, y Pere YSÀS: "La Historia social...", art. cit., p. 136. 
liberales, laicas y republicanas. La configuración de una "sociedad de consumo" en los años sesenta, vinculada al crecimiento económico, ayudó a generar una aceptación del régimen. Paradójicamente, el inmovilismo gubernamental ante ciertas cuestiones sociales y culturales deparó actitudes conflictivas pasivas y activas. Las clases medias católicas, en la periferia, exteriorizarán comportamientos diferentes en función de la intensidad y la virulencia de los conflictos sociales e ideológicos vividos ${ }^{65}$. En cualquier caso, País Vasco y Cataluña fueron siempre focos de disidencia, aunque en muchos casos relegada al ámbito privado. Tal y como recoge Sevillano Calero, en la región catalana no se consiguió una influencia ideológica notable ni un apoyo masivo y entusiasta, pero se impuso la pasividad politica y social66. Por último, en cuanto a las clases trabajadoras, Molinero e Ysàs explican que durante el primer franquismo optaron por posiciones discrepantes que no se reflejaron en acciones multitudinarias de protesta, sino más bien en actitudes pasivas y sumisas ante el miedo, ya comentado anteriormente, que estaba vinculado a la represión. El régimen consiguió neutralizarlos, pero no conquistarlos: la pasividad no significaba indiferencia o aceptación, simplemente la búsqueda prioritaria de la subsistencia. Los apoyos vinieron por diversas circunstancias de ciertos sectores sociales: ideológicas, religiosas y económicas (por ejemplo, los beneficios laborales que les reportaban haber participado en el conflicto del bando nacional). La preocupación del régimen por ganarse el favor de estos sectores sociales se reflejó en economatos, acceso a viviendas baratas, avances de la Seguridad Social o buenas condiciones de jubilación ${ }^{67}$. Los años sesenta supondrán el incremento de la oposición obrera manifiesta y el abandono de la pasividad ante la mejora de las condiciones de vida y la disminución del miedo entre las nuevas generaciones de obreros industriales.

\subsection{Estrategias de captación social}

En comparación con el régimen nacionalsocialista y fascista, continúa en su obra Saz Campos, el franquismo no entendió la violencia como una herramienta transitoria que diera paso a nuevos mecanismos de inclusión y movilización de las masas. Se propuso, obviamente, el apoyo popular dentro del mundo obrero, como demostrará la Unión Naval de Levante o los Altos Hornos del Mediterráneo; sin embargo, la pasividad ciudadana también se debía a un Estado que no se esforzó en lograr un consenso entusiasta y ampliamente activo, que no configuró un proyecto comunitario y revolucionario de integración y movilización, sino que procuró una sociedad despreocupada políticamente. La guerra y el genocidio étnico no formaban parte del objetivo franquista al no existir una necesidad de moldear la pertenencia a la comunidad a través de la identificación del enemigo exterior, como ocurría en el caso de la Volksgemeinschaft. Finalmente, el catedrático español considera que a nivel cronológico debe establecerse una distinción entre los primeros años, los años del terror, la humillación, el hambre y la miseria, y la segunda década, donde la re-

65 Ibid., p. 138.

66 SEVILLANO CALERO, Francisco: "Consenso y violencia...", art. cit., p. 162.

${ }^{67}$ SAZ CAMPOS, Ismael: Fascismo y..., op. cit., p. 194. 
presión se aminoró, la pobreza sustituyó a la miseria, se estableció una "normalidad sin politica" y la oposición atravesó su mayor crisis ${ }^{68}$.

Ahora bien, frente a la tesis que afirmaba la inexistente búsqueda por parte del franquismo de un consenso activo, sustentada en la nula movilización social y el simple intento de obediencia, Molinero e Ysàs defienden la idea de un franquismo preocupado por las opiniones y actitudes de los españoles a través de la ejecución de diversos proyectos (de modesto resultado favorable ante los escasos recursos aportados por el Nuevo Estado) con los que ganar el favor de distintos sectores sociales. La satisfacción de las aspiraciones sociales de las masas se concibió como un mecanismo de control social y generador de consenso, sustentado en la idea de la patria como madre protectora de sus miembros. Habría, desde luego, diferentes grados de aceptación de estas politicas. Tal y como explica León Álvarez, los obreros con mayor conciencia de clase y de la situación politica [...] mantendrian una postura distante y poco receptiva frente a otras personas que, ante su menor grado de politización, se mostrarian receptivas al discurso populista del franquismo ${ }^{69}$.

La preocupación del bando nacional por "atraer" a los españoles se plasmará en la creación durante la Guerra Civil de Auxilio Social, una organización cuya finalidad caritativa la podriamos comparar con la Winterhilfsswerk nazi. La politica de reconstrucción nacional que pretendia -ayudando a individuos, especialmente infantes, de cualquiera ascripción ideológica- era escasamente llevada a la práctica: en palabras de Molinero, diversos trabajos han mostrado el adoctrinamiento, coacción $y$, con frecuencia, el menosprecio con que fueron tratados los hijos de los vencidos ${ }^{70}$. Auxilio Social era un mecanismo de propaganda política e integración comunitaria, organizando y desarrollando desde 1937 el Servicio Social de la Mujer: las jóvenes debían colaborar en recolectas públicas al menos tres veces durante el tiempo que duraba dicho servicio. Servicio Social pasaría a estar controlado, desde diciembre de 1939, por la Sección Femenina, organismo que - junto con el Frente de Juventudes - llevaría a cabo, al margen del control social y de la obvia labor propagandística, obras asistenciales a personas desfavorecidas. Como recoge Carmen Molinero, en los años cuarenta, en un contexto de hambre y enfermedades frecuentes por subalimentación y falta de medicinas, una de las primeras actuaciones del Frente fue ofrecer merienda y atenciones sanitarias a los niños y jóvenes afiliados ${ }^{71}$.

La demanda de apoyos sociales por parte del régimen se cimentó, en cierta medida, en la publicitación de organismos destinados a solventar necesidades sociales, especialmente en el ámbito familiar. La protección comunitaria aparece en el franquismo asociada al Gobierno, ya que el instrumento básico de politica social - el Ministerio de Trabajo-y, en consecuencia, todos sus organismos anejos (Instituto Nacional de Previsión, organizado en torno a los

68 Ibid., p. 195.

69 LEÓN ÁLVAREZ, Aarón: Consenso y resistencia en Canarias durante el primer franquismo, Santa Cruz de Tenerife, Idea, 2008, p. 133.

70 MOLINERO, Carmen: "La politica social del régimen franquista. Una asignatura pendiente de lahistoriografia", en Ayer, n. ${ }^{\circ}$ 50, 2003, p. 321.

71 Ibid., pp. 324-325. 
ámbitos de accidentes de trabajos, subsidios familiares, enfermedad, vejez y seguros libres; Mutualidades...), estaban en manos de Falange. Además, la Organización Sindical Española (OSE), creadora de diversos organismos como "Previsión Social» — centrada en el mundo rural—, o "Servicio del Seguro de Enfermedad", también se hallaban bajo su control. Vemos, por tanto, que el partido único, a pesar de depender del Estado, alimenta el aparato institucional, la burocracia estatal y dirige las organizaciones de masas. Creada la Vicesecretaría Nacional de Obras Sindicales en 1941, la Obra Sindical del Hogar, en colaboración con el Instituto Nacional de la Vivienda, se constituirá como el organismo emblemático de la OSE y un instrumento destacado para la obtención de consenso desde el ámbito sindical ${ }^{72}$. Asimismo, la Obra Sindical Educación y Descanso vino a emular la función de la Opera Nazionale Dopolavoro o de la KraftdurchFreude: se intentó, por ejemplo, impulsar el Hogar del Productor, la reutilización de antiguos espacios populares de reunión marxista destinados al descanso de los trabajadores afines al régimen.

Por último, el Fuero del Trabajo (1938), la primera ley fundamental del Nuevo Estado, fue la base de la que partió el "Régimen Obligatorio de Subsidios Familiares", cuyo objetivo era dotar al trabajador masculino de los bienes necesarios para la subsistencia de su prole, evitando de esa manera que la madre abandonara su función primordial en el hogar con el fin de obtener un trabajo. También cabe destacar los préstamos de nupcialidad y de natalidad en materia demográfica y de género, o el Seguro Obligatorio de Enfermedad (1942), el cual repara Molinero que si bien representó un avance considerable para amplios sectores de trabajadores, no fue asi para buena parte de los asalariados de las zonas más industrializadas de España73; o el Plus de Cargas Familiares (1945), medida surgida ante la insignificancia que suponía el subsidio como ingreso salarial. La distribución en el seno de la empresa de los "puntos" se realizaba atendiendo al estado civil y al número de hijos del trabajador. Estas ayudas, escasas si las valoramos desde una óptica general europea, eran bien vistas por la población al no conocer la realidad exterior y, por tanto, creer que la propaganda respondia a la realidad y que el régimen franquista era un abanderado de la protección social ${ }^{74}$. El Ministerio de Trabajo, dirigido desde 1941 por José Antonio Girón, fijó los salarios de los trabajadores hasta 1958, momento en que se aprobó la Ley de Convenios Colectivos. Al margen de la coacción laboral, el ministerio también ejerció, como se ha dicho, una labor social. El 18 de julio se convirtió en fiesta de Exaltación del Trabajo, fecha de inicio del "glorioso alzamiento" y que distaba mucho de la celebración obrera del 1 de mayo: el objetivo era enaltecer la hermandad productora y el trabajo como servicio a España. Esto no quiere decir que este último día citado no fuera importante para los falangistas: organizaban durante dicha jornada diversos actos en determinadas áreas industriales donde instaban la complicidad de los trabajadores. Girón deseaba atraerse lo más posible a las masas obreras, especialmente a los mineros asturianos, a través de una retórica populista. Ismael Saz nos traslada al

72 MOLINERO, Carmen: "El reclamo de la "justicia social" en las politicas de consenso del régimen franquista", en Historia Social, n. ${ }^{\circ}$ 56, 2006, p. 104.

73 MOLINERO, Carmen: "La politica social...", art. cit., p. 327.

${ }^{74}$ MOLINERO, Carmen: "El reclamo de la...", art. cit., p. 107. 
mundo fabril de la zona costera valenciana a través de un estudio del astillero Unión Naval de Levante. Su objetivo era analizar las formas de vida y actitudes sociales en el territorio durante el primer franquismo, entrevistando a 10 trabajadores entre 68 y 88 años. Uno de los individuos interpelados afirmará sobre Girón lo siguiente: [...] apoyó el desarrollo de la "Benéfica"; fue decisivo para que los trabajadores accedieran a las viviendas construidas para ellos en las mejores condiciones; concedió sustanciales aumentos salariales y pagas extraordinarias $[\ldots]^{75}$.

En definitiva, la pregunta que debemos hacernos ante lo expuesto es: ¿en qué medida la represión, la destrucción de espacios de sociabilidad popular y la intervención en el ocio perjudicó las políticas destinadas a captar el favor de las masas y fomentó la pasividad? La magnitud en la represión y las pésimas condiciones de vida que perduraron más de una década podrian explicar la escasa capacidad para forjar consenso por parte del régimen (no hemos de olvidar que en Alemania, por ejemplo, la llegada de los nazis vino unida a la mejora de la economia, hecho que no ocurrió en el franquismo). A estos factores se unirian la insignificancia de la inversión en gasto social y la primacia de la disciplina sobre la atracción en las relaciones sociales ${ }^{76}$. Acerca de las distintas organizaciones sociales que conformaron el régimen, la misma autora expresará la siguiente afirmación: [...] en España no puede hablarse de Estado de bienestar hasta la instauración del régimen democrático, dado que tal concepto conlleva - además de un mayor volumen de prestaciones sociales que las que se daban en España- una voluntad redistributiva y una aplicación universal77.

\section{6. ¿Qué podemos concluir?}

\subsection{Más allá de la dicotomía "consenso-disenso"}

Consentimiento y consenso difieren en algunos aspectos de su definición, algo que no ocurre en el idioma italiano, donde ambos conceptos se utilizan por igual. El primero se trata de una actitud activa de afirmación o aprobación que, independientemente del estado de ánimo del individuo que lo enuncia, otorga permisibilidad a las politicas del Estado. El consenso, además, hace referencia a un acuerdo conjunto, compartido, que se sustenta en la conformidad de las partes involucradas. Cabana Iglesia afirma que el consentimiento no remite a la armonía entre los dos sujetos ni denota un grado de cohesión significativo, como si lo hace el concepto de consenso ${ }^{78}$.

Una vez aclarado esto, hemos comprobado cómo el fenómeno del consenso no debe analizarse desde parámetros absolutos y cerrados; en otras palabras, en la interpretación histórica no existen solo situaciones blancas y negras, puede haber grises. La dicotomía consenso-disenso se rompe e irrumpen en

\footnotetext{
75 SAZ CAMPOS, Ismael: Fascismo y..., op. cit., pp. 231-232.

76 MOLINERO, Carmen: La captación de masas..., op. cit., p. 198.

77 MOLINERO, Carmen: "La política social...", art. cit., p. 329.

78 CABANA IGLESIA, Ana: "De imposible consenso. Actitudes de consentimiento hacia el franquismo en el mundo rural (1940-1960)", en Historia Social, n. ${ }^{\circ}$ 71, 2011, p. 92.
} 
el discurso historiográfico otros vocablos (aceptación pasiva, indiferencia, resignación, etc.) que permiten englobar la extensa zona intermedia en la que se movieron las distintas actitudes ciudadanas. No todos los ciudadanos se comportaban del mismo modo, respondian de la misma manera ante diversas acciones del régimen ni poseían los mismos deseos, inquietudes o expectativas; algunos, incluso, llegaban a adoptar posiciones contradictorias. Los sujetos históricos no constituyen grupos definidos y puros. Algunos individuos podian aceptar el régimen por lo que este ofrecia en términos de consenso pasivo -orden, paz, trabajo, mejora individual-y rechazar los mecanismos y apelaciones propias de la articulación del consenso activo ${ }^{79}$. Es decir, se han de tener en cuenta también aquellos factores materiales e ideológicos que pueden influir en la configuración de una actitud. Un ejemplo de ello son las clases burguesas, cuyo apoyo al régimen franquista, según Molinero e Ysàs, no fue uniforme, ya que en algunos sectores iba acompañado de una adhesión plena y activa mientras que en otros aspectos el régimen fue consentido pasivamente, incluso como "mal menor" ante la ausencia de alternativas satisfactorias ${ }^{80}$. Atender a las 36 actitudes ciudadanas durante el franquismo implica reflexionar sobre la perdurabilidad de esta dictadura en el tiempo y cómo fueron modificándose las circunstancias por las que atravesó el régimen y la sociedad a lo largo de décadas. Es preferible hablar de aceptación o de consentimiento en lugar de consenso, pues las medidas tomadas a fin de conseguir la adhesión activa o pasiva de los españoles nunca fueron establecidas a través de un pacto previo con estos.

\subsection{La desvirtuación de la realidad y el problema de las fuentes}

Durante muchos años, el binomio disenso y consenso ha nutrido los estudios historiográficos sobre regímenes fascistas, sustentados estos últimos en la búsqueda de un orden social donde el sacrificio individual será legitimado para lograr el bienestar colectivo; dichos fascistas se postularán como los únicos capaces de lograr tal bienestar, utilizando para ello todos los medios necesarios. Ahora bien, el consentimiento puede reflejar una realidad social muy distorsionada: la coacción y la amenaza se antojan elementos clave con objeto de influir en la toma de decisiones individuales. La incertidumbre ante las situaciones económico-sociales venideras y la emergencia de determinadas necesidades de subsistencia configuran, junto al miedo a la represalia, algunos de los motivos principales de apoyo popular al fascismo, de confianza en sus promesas, aun cuando se discrepe de sus métodos. El consentimiento manifestado con una amenaza subyacente, sin libertad de conciencia, no es un consentimiento real. Muchos historiadores, como Paul Corner, han insistido en la idea de que, si no existe una variada gama de opciones para elegir inevitablemente se optará por la única existente; no había posibilidad de ser antifascista, no existía esa elección. En palabras de Ian Kershaw, en el caso de que los comentarios registrados reflejaran fielmente las actitudes públicas [...], dichas actitudes podrian resultar más de la expresión de una conformidad más o menos sujeta a coerción que de la auténtica popularidad de Hitler ${ }^{81}$. La

\footnotetext{
79 SAZ CAMPOS, Ismael: Fascismo y..., op. cit., p. 181.

80 MOLINERO, Carmen, y Pere YSÀS: "La Historia social...", art. cit., p. 137.

81 KERSHAW, Ian: El mito de Hitler..., op. cit., p. 22.
} 
mayoria de autores se basan en diarios, registros, correspondencia, encuestas... como fuente de sus investigaciones. Ahora bien, ¿cuánto de fiables y verdaderas son dichas fuentes? Para el caso franquista, no resulta sencillo conocer las opiniones y actitudes politicas de una ciudadanía sometida a una dictadura que castigaba o penalizaba la discrepancia, la protesta, el rechazo o la oposición, y donde eran monopolizados los medios de comunicación. E1 análisis de la documentación oficial puede verse alterado por las autoridades, capaces de minimizar o exagerar aspectos tales como el apoyo popular al régimen, el disentimiento o las relaciones de poder entre las distintas fuerzas politicas $^{82}$.

\subsection{Distintos países, distintas transformaciones}

La historiografía ha evolucionado de manera distinta en el análisis del fascismo italiano, el nacionalsocialismo alemán y el franquismo español. Reconocer un consenso entre la población alemana, dada la brutalidad de los hechos llevados a cabo durante la dictadura de Adolf Hitler, supuso un reto más dificil de asumir por los historiadores, especialmente si Alemania no quería ver más empañada su imagen en el nuevo escenario politico internacional. Italia, por su parte, se concebía como un modelo de menor relevancia, alejado de la radicalización y criminalidad alemana, por lo que admitir la importancia del consentimiento popular se antojaba más aceptable: una culpabilidad colectiva derivaria, de forma más sencilla, en una absolución colectiva. Además, el final del fascismo en ambos países no se desarrolló de la misma manera: mientras en territorio italiano la resistencia partisana marcó la historia de la región desde 1943 -lo que, de alguna manera, "limpia" su imagen-, en Alemania el nazismo imperó hasta los últimos días de su existencia. En el caso del régimen de Franco, los binomios inclusión-exclusión, consenso activo-consenso pasivo y consenso-coerción funcionaron de modo distinto ${ }^{83}$. Los análisis sociales del régimen franquista apuntarán a un abanico de actitudes diferentes que vendrán definidas a partir del sector social analizado, el momento o la fase histórica de la dictadura que se estudie y el enfoque nacional o regional empleado. Añadamos que tampoco fue similar la movilización de las masas y la conformación de un sentimiento nacionalista como elemento de cohesión e integración politica. A diferencia de lo ocurrido en las dictaduras de Hitler y Mussolini, en las que la participación y el apoyo popular es fundamental para entender su evolución y se intenta institucionalmente evitar la apatía, en el paradigma del régimen franquista se puede llegar a considerar la despolitización y la desmovilización de la sociedad como un éxito: el conformismo y el individualismo cimentarian la pasividad y el apoliticismo de los españoles. El régimen se conformó con la fidelidad de determinados sectores y con la seguridad de que el grueso de la población no amenazara a la seguridad del Estado.

\subsection{La importancia del sujeto y sus actitudes pasivas/activas de apoyo}

En la década de los sesenta y los setenta la historiografia italiana vivió una transformación analítica a partir de la obra biográfica de Benito Mussolini realizada por Renzo de Felice. Este abrió la puerta a la idea de consenso en el

82 HERNÁNDEZ BURGOS, Claudio: Franquismo a ras de suelo..., op. cit., p. 30.

83 SAZ CAMPOS, Ismael: Fascismo y..., op. cit., p. 177. 
régimen fascista, desatando así un nuevo debate en torno a la configuración del movimiento en la primera mitad del siglo xx; un debate enmarcado en los nuevos arquetipos postmodernistas o culturales que, frente a la historiografia socioeconómica, analizarán al individuo en sus circunstancias, indagarán en la relevancia del discurso ideológico y político. Detractores y partidarios del historiador reatino protagonizarán una discusión académica sobre el protagonismo (o su ausencia) que la violencia y la coacción adquirieron en la conformación del régimen y de la opinión pública. El "giro cultural" de los años setenta conlleva la elaboración de estudios sobre el fascismo vertebrados en torno a la importancia de los símbolos, los rituales, los discursos o el lenguaje audiovisual en la configuración de un sentimiento de pertenencia a una causa, a un colectivo, a una nación. Autores como Robert Gellately, Daniel Jonah Goldhagen o Hans Fritzsche no niegan el uso de la violencia por parte de los nazis, pero sí la minimizan y relegan a un segundo plano desde la óptica de otros historiadores como Richard Evans. La represión la interpretaban como una fase provisional, transitoria, que daba paso a un periodo de paz politica cuyos mecanismos de control policial y herramientas de integración en la comunidad adquirian mayor protagonismo. Se presentan, de alguna manera, dos tipos de interpretaciones: por un lado, una visión simbólico-politica que otorga protagonismo a la movilización de las masas y a la elaboración de una mitología nacionalista; por otro lado, una perspectiva socioeconómica que, para el caso alemán, se sustentaba en la mejora de la economía y la calidad de vida. Algunas de las mayores herramientas que los fascistas emplearán para la construcción de un consenso activo serán las organizaciones sociales que beneficien principalmente a las clases trabajadoras, el control de la formación juvenil y su participación en obras de caridad, la movilización de las masas a través de grandes eventos de exhibición propagandística, etc. El crecimiento del apoyo al nacionalsocialismo, por ejemplo, partirá de un principio multicausal: un factor económico (crisis laboral), un factor político (desprecio hacia la República de Weimar) y un factor social (búsqueda de la seguridad y el orden y rechazo del comunismo). En la vía hacia un consenso pasivo y la «despolitización" de la sociedad por parte del franquismo se optará por el adoctrinamiento educativo y religioso, el desarrollo de políticas de ayuda asistencial como Auxilio Social, la construcción de un espacio público de homenaje y recuerdo para los vencedores de la guerra, la utilización de la propaganda o las mejoras económicas de los años sesenta. A ello se unirá el miedo a la represión y el objetivo prioritario de la subsistencia en los primeros años del régimen. 